\title{
Sub-10-micrometer Toughening and Crack Tip Toughness of Dental Enamel
}

\author{
Siang Fung $\underline{A n g}^{a}$, Anja Schulz ${ }^{a}$, Rodrigo Pacher Fernandes ${ }^{a}$, Gerold A. Schneider ${ }^{\mathrm{a}}{ }^{, *}$ \\ ${ }^{a}$ Institute of Advanced Ceramics, Hamburg University of Technology, Denickestr. 15, 21073, \\ Hamburg, Germany.
}

\begin{abstract}
In previous studies, enamel showed indications to occlude small cracks in-vivo and exhibited R-curve behaviors for bigger cracks ex-vivo. This study quantifies the crack tip toughness $\left(K_{I O}, K_{I I I O}\right)$, the crack closure stress and the cohesive zone size at the crack tip of enamel and investigates the toughening mechanisms near the crack tip down to the length scale of a single enamel crystallite. The crack-opening-displacement (COD) profile of cracks induced by Vickers indents on mature bovine enamel was studied using atomic force microscopy (AFM). The mode I crack tip toughness $K_{I 0}$ of cracks along enamel rod boundaries and across enamel rods exhibit similar range of values: $K_{I O, I}=0.5-1.6 \mathrm{MPa} \cdot \mathrm{m}^{0.5}$ (based on Irwin's 'nearfield' solution) and $K_{I O, c_{2}}=0.8-1.5 \mathrm{MPa} \cdot \mathrm{m}^{0.5}$ (based on the cohesive zone solution of the Dugdale-Muskhelishvili (DM) crack model). The mode III crack tip toughness $K_{I I I, \text {,Ir }}$ was computed as $0.02-0.15 \mathrm{MPa} \cdot \mathrm{m}^{0.5}$. The crack-closure stress at the crack tip was computed as 163-770MPa with a cohesive zone length and width 1.6-10.1 $\mu \mathrm{m}$ and 24-44nm utilizing the cohesive zone solution. Toughening elements were observed under AFM and SEM: crack bridging due to protein ligament and hydroxyapatite fibres (micro- and nanometer scale) as well as microcracks were identified.

Keywords: enamel, crack tip toughness, cohesive zone, hierarchical structure, toughening mechanisms.

* Corresponding address: Institute of Advanced Ceramics, Hamburg University of Technology, Denickestr. 15, 21073, Hamburg, Germany. Tel.: +49 4042878 3037; fax: +49 4042878 2647. E-mail address: g.schneider@tuhh.de (G.A. Schneider).
\end{abstract}

\section{Introduction}

Enamel is the outermost layer of teeth. Throughout our lifetime, enamel remains intact despite millions of mastication loadings in the form of compression, shear and torsion. These result in a distribution of cracks in enamel (Bodecker, 1953; Chai et al. 2009). Despite, enamel could be considered as a damagetolerant material against crack propagation due to the following reasons. Small cracks in enamel of $40 \mu \mathrm{m}$ deep and $8 \mu \mathrm{m}$ wide were observed to be occluded by mineral deposition, proposed as a key phenomenon to repair tiny enamel cracks in vivo (Hayashi 1994). Studies of ex-vivo cracks over larger distances have shown that enamel exhibits R-curve behavior; the stress intensity increased from values between 0.5 and $1.5 \mathrm{MPa} . \mathrm{m}^{0.5}$ up to $2.5 \mathrm{MPa} . \mathrm{m}^{0.5}$ at $1.5 \mathrm{~mm}$ crack extension in human enamel (Bajaj and Arola, 2009a) and up to $4.4 \mathrm{MPa} . \mathrm{m}^{0.5}$ at $500 \mu \mathrm{m}$ crack extension in bovine enamel (Bechtle et al. 2010a). The reported toughening mechanisms are crack bridging of tissue ligaments of $\sim 10 \mu \mathrm{m}$ wide or bigger, microcracking, possible bridging by protein ligaments and crack deflection promoted by enamel rod decussations mainly existing in the inner enamel (Bajaj and Arola, 2009b; Bajaj et al., 2008).

The teeth of all mammals appear to be very similar on a histochemical basis (Oesterle et al. 1998). As a reference, the composition of human enamel varies about $\sim 90 \mathrm{vol} \%$ of hydroxyapatite (HAP) crystallites, $\sim 8 \mathrm{vol} \%$ of water and $\sim 2 \mathrm{vol} \%$ of organic matrix (Healy, 1998). In some studies, bovine enamel were used to substitute human enamel (Nishimura et al., 2008; Ruse et al., 1990) due to their structural similarity (Sanches et al., 2009) that can be described by three hierarchical structural levels. The elementary construction unit consists of $\sim 50 \mathrm{~nm}$ diameter apatite fibers (Sanches et al., 2009; Glimcher et al., 1965) that are probably surrounded by $1-2 \mathrm{~nm}$ thin organic layer, observed earlier in human enamel (Frazier, 1968). These nanofibers are closely-packed to form the first level 
hierarchical structure - 3.7-8.8 $\mu \mathrm{m}$ rods (Sanches et al., 2009) that span from the dentino-enamel junction (DEJ) to near tooth surface (Gray et al., 1995). 'Interrod substance' was observed in between rods where the crystallite orientations are significantly different from those in the center of the rods (Bajaj and Arola, 2009a; Bechtle et al., 2010b; Glimcher et al., 1965). The less dense 'interrod' regions are accumulated with proteins and water, thus appear as distinct protein-rich structures (Maas and Dumont, 1999). Bundles of these rods including the interrod regions create the second hierarchical layer. Groups of enamel rods have same local orientations but different from the adjacent groups of enamel rods, they formed bands called Hunter-Schreger Bands as the third level of hierarchical structures (Ten Cate, 2003).

It is well-known from ceramic materials that toughness measurements with SingleEdge-Notch-Beam (SENB) or CompactTension (CT) specimens are usually not able to measure the crack tip toughness, $K_{I 0}$, in particular when steep crack resistance curves prevail (Fett et al., 2008; Fünfschilling et al., 2009; Özcoban et al., 2010). In brittle materials the most common used method to measure $K_{I 0}$ is to measure with high spatial resolution using an atomic force (AFM) or scanning electron microscope (SEM) the crack opening displacement (COD) in the crack tip region (Kounga Nijwa et al., 2003; Rödel et al. 1990; Meschke et al., 1997, 2000). With this information Irwin's crack tip solution (Irwin, 1958; Lawn 1993) is applied to evaluate $K_{I 0}$.

In enamel a crack tip toughness study based on COD measurements is missing which is the objective of this investigation. AFM is used as a high spatial resolution tool for COD measurement to calculate $K_{I 0}$ (Irwin, 1958; Lawn 1993). The information is also used to apply a cohesive zone models developed by Goodier and Field (Goodier and Field, 1963; Hahn, 1976; Hahn and Rosenfeld, 1965) for the Dugdale-Muskhelishvili crack model (Dugdale, 1960; Muskhelishvili, 1953) to compute the closure stresses at the crack tip, the cohesive zone width and length, as well as the corresponding crack tip toughness. In addition to AFM, SEM is also used to investigate toughening mechanisms around and behind the crack tip.

In a number of other studies [Bajaj and Arola, 2009a, 2009b; Bechtle et al., 2010; Bajaj et al., 2008] enamel's toughening mechanisms are already reported but not with a special focus on the different lengths scales. As enamel is hierarchically structured the objective is to identify the specific toughening mechanisms on the first and second hierarchical level as defined above using AFM and SEM.

\section{Experiments}

(A) Specimen preparation: Mature bovine incisors were used due to their larger amount of enamel compared to human teeth. The bovine teeth are stored in Hanks' Balanced Salt Solution (HBSS) before sample preparation. The rectangular prisms of $\sim 3 * 2 \mathrm{~mm}^{2}$ were first cut out from the labial side of mature bovine incisors (Fig. 1(a)) by using a saw (Brüder Mannesmann 92571, Germany) under water irrigation. The cows were sacrificed between 3-4 years old. The specimen surface was first grinded with an abrasive paper of grit 4000 . It was further polished with diamond suspensions of $1 \mu \mathrm{m}$, $0.25 \mu \mathrm{m}$ and finally $0.05 \mu \mathrm{m}$ (Bühler, Germany). The polished tooth was then glued face-up on a steel plate with wax for subsequent investigation on the same day. A total of 15 specimens were investigated (13 specimens under AFM and 2 specimens under SEM).

(B) Vickers indents and AFM measurements: The freshly polished enamel surfaces were introduced with Vickers indents of $400 \mathrm{~g}$ for $10 \mathrm{~s}$ (3212, Zwick $\mathrm{GmbH}$, Germany). An example is shown in Fig. 1(b). Without the introduction of the Vickers indent, no cracks were observed on the specimens following the same polishing procedures and examined under AFM with the same experimental conditions. The weight of $400 \mathrm{~g}$ was selected because the induced crack lengths were long enough that the crack lengths to indentation size ratio was bigger than 3. Yet, they should not be too long; due to the fact that scanning of high resolution pictures with AFM is extremely time consuming, excessive crack lengths would lower the chance to find the crack tip within one day after sample preparation and therefore are undesirable. 3-5 indents were made on the polished surface of each specimen; they were at least $500 \mu \mathrm{m}$ apart. Only one specimen was investigated within a day. No samples are re-used overnight because polished samples, if left immersed in HBSS solution for rehydration overnight, were 
a

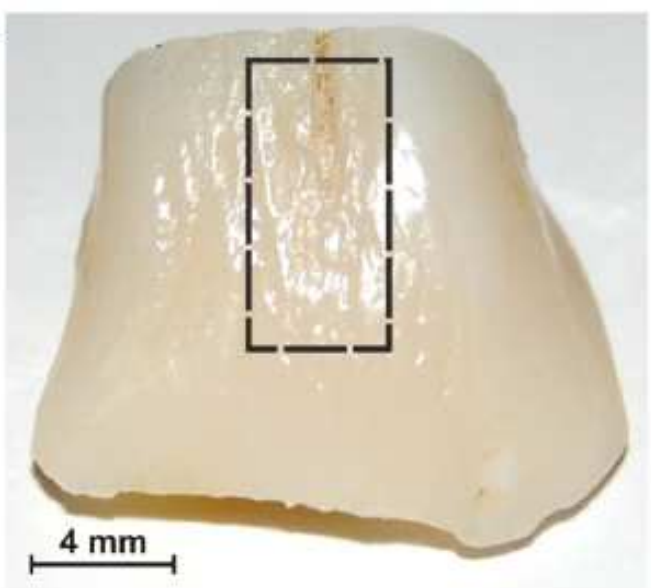

C

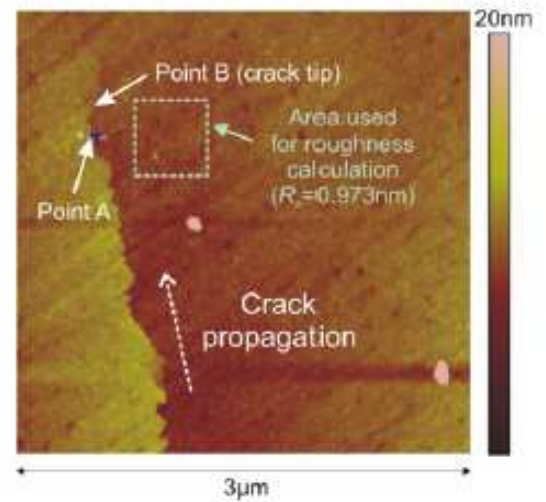

e

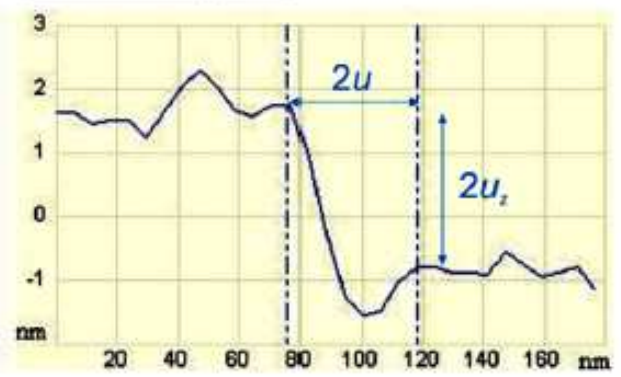

b

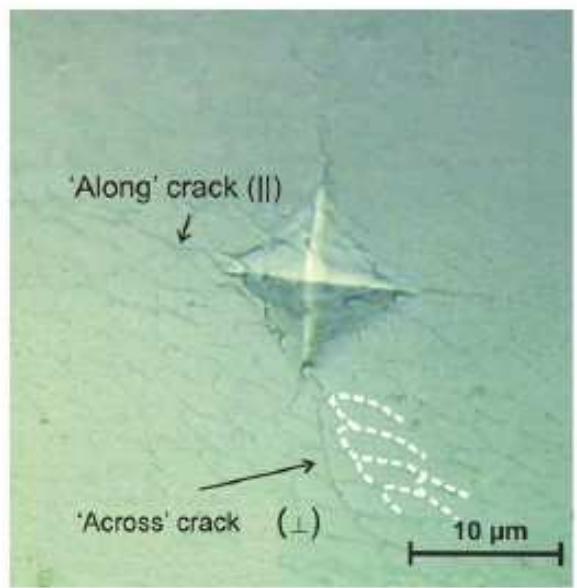

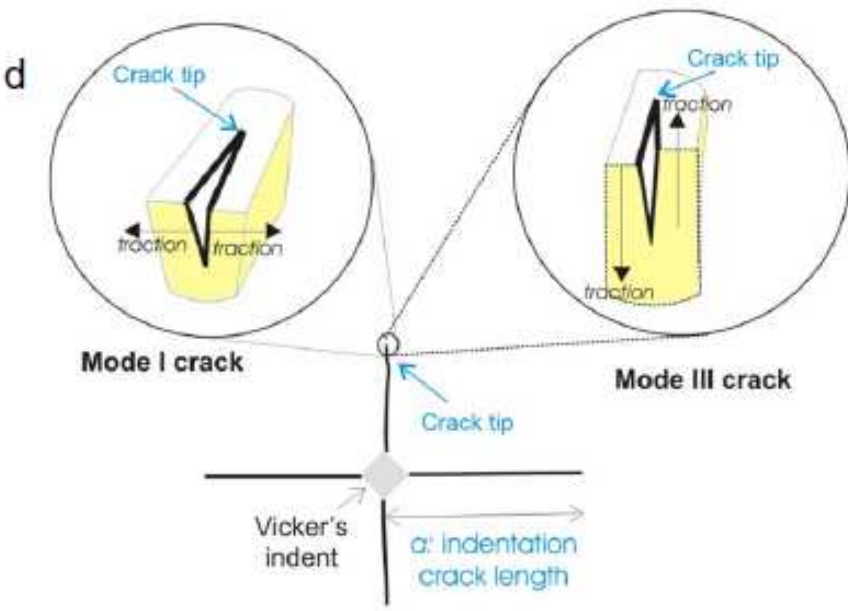

f

\section{Cross-section at point B (crack tip):}

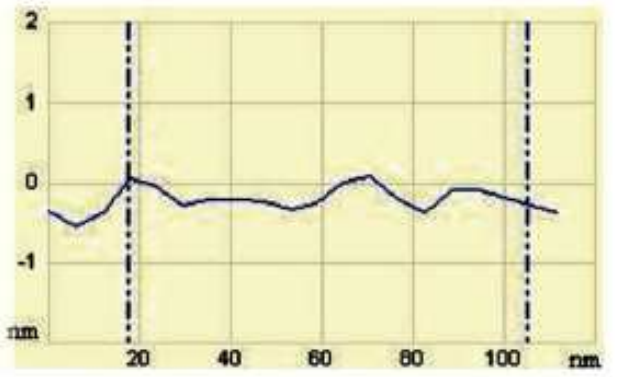

Fig. 1: Vicker's indent and COD measurements. (a) A bovine teeth. The indicated area were cut out and polished for investigation. (b) A Vicker's indent observed under an optical microscope. The 'along' crack (going mainly along enamel rod boundaries) and the 'across' crack (going mainly across the enamel rods) are labeled. The results for both types of cracks are labeled with subscript ' $\|$ ' and ' $\perp$ ' in the article. (c) An AFM topography image of a well-polished enamel surface with a crack and its crack tip. The rectangular box is a chosen area for roughness analysis $\left(R_{a}=0.973 \mathrm{~nm}\right)$. (d) Illustration of the mode I and mode III fracture at the crack tip of a Vicker's indent. (e) A cross-sectioned topography profile corresponding to the white line at point A in (c), used to calculate $u$ and $u_{z}$ of that point, for the calculation of $K_{I 0}$ and $K_{I I I 0}$ respectively. (f) A cross-sectioned topography profile corresponding to the white line at point $\mathrm{A}$ in (c) where the crack could not be differentiated from the surface roughness and is defined as the crack tip for the crack. 
covered with a layer of salt deposition that precludes nanoscale observation of the sample surface under AFM. Only one crack (from one specimen) could be investigated in one day. The indents were first observed under light microscope (Aristome, Ernst Leitz Wetzlar, Germany). Then, the crack profiles were examined under AFM (Dimension 3100, Veeco, USA) in tapping mode. Cracks with insufficient crack lengths were discarded. We calculated the total crack lengths by summing up the lengths under the optical microscope attached with the AFM system and the AFM topography scans. All the measurements were carried out in air environment.

As the darker contrast in the AFM topography images belongs to lower topography levels, the crack can be identified as a dark contrast due to the deeper position of the AFM tip. A X-Y sample stage was used to trace the cracks away from the Vickers indents as far as the crack tips. Super sharp tips with tip apexes <10nm (SuperSharpSilicon, Nanosensors, Switzerland) were used together with a slow scanning frequency of $0.2 \mathrm{~Hz}$ to acquire high resolution images (an example is shown in Fig. 1(c)). The height profiles across the crack at desired positions are later obtained from the topographical images to measure the COD between two opposing crack walls $(2 u)$ as well as the height difference $\left(2 u_{z}\right)$ (Fig. $1(\mathrm{e})$ ), both as a function of the distance from the crack tip $(X)$. The COD measurement was stopped when the crack could no longer be differentiated from the surface roughness, this position is taken as zero position for $X$ (Fig. 1(f)). The resolution of AFM measurement depends on the tip radius, which is $<10 \mathrm{~nm}$ here as well as the nominal lateral resolution of the AFM system, which is $2 \mathrm{~nm}$ for the evaluation of a $1 \mu \mathrm{m} \times 1 \mu \mathrm{m}$ topography section. Therefore the uncertainty in the COD measurement is $\leq 10 \mathrm{~nm}$.

(C) SEM investigations: Vickers indents $(1 \mathrm{~kg}, 10 \mathrm{~s})$ were made on the 2 polished specimens. Higher weight of Vickers indents load $(1 \mathrm{~kg})$ was chosen so that the resulted crack profiles are longer and clearer for observation under SEM. Two indents per specimen were made. The surface were cleaned with ethanol and dried for one day in a desiccator. The samples were contacted with silver paint in the edges and carbon pad in the bottom to avoid the build up of charges during the measurements. SEM images were recorded using the secondary electron signal with an acceleration voltage of $5 \mathrm{kV}$.

\section{Results}

The surface roughness, $R_{a}$ of our enamel specimens over an area of $500 \times 500 \mathrm{~nm}^{2}$ is less than $1 \mathrm{~nm}$ (Fig. 1(c)). $\left(R_{a}\right.$ is the arithmetic average of the absolute values of the surface height deviations measured from the mean plane.) Out of the 13 specimens investigated under AFM, only 6 CODs are used (Tab. 1). For the other cracks, either the observed crack tips were too close to microcracks or bridges, the crack lengths were too long and the crack tips could not be traced until the end of the day, or when the crack tips were identified, the crack lengths were too small. The cracks propagating mainly along rod boundaries are termed 'along' (Fig. 1(b), Fig. 4(a)) whereas those propagating across the rods are termed 'across' (Fig. 1(b), 4 (b), 5(a)). The terms 'longitudinal' and 'transverse' (Bechtle et al., 2010a) (also illustrated in Fig. 6) are not used because they usually describe the rod orientations relative to the cross-sectional plane but not the manner of crack propagation. The enamel rods in this study are oriented in an oblique orientation relative to the sample surface plane, judging from their pro-longed shape in the pictures (Fig. 1(b), 4 and 5), hence neither 'longitudinal' nor 'transverse'. The 'along' and 'across' cracks are typically longer than $100 \mu \mathrm{m}$ and $50 \mu \mathrm{m}$ respectively. Cracks with insufficient crack lengths are discarded. The results for 'along' and 'across' cracks are labeled by subscript ' $\|$ ' and ' $\perp$ ' accordingly.

(A) Determination of crack tip toughness: The measured in plane and out of plane misplacements $u$ and $u_{z}$ (Fig. 1 (e)) are used to determine the mode I and mode III crack tip toughness respectively. Mode I fracture is a tensile mode separation where the traction forces act to open crack surfaces directly apart from each other, whereas mode III fracture is a shear mode separation where the traction forces act parallel to the crack plane and also parallel to the crack front (Fig. 1(d)).

The measured half crack opening profiles $(u)$ versus crack length behind the crack tip $(X)$ are shown in Fig 2(a) and are used to calculate $K_{I O, I r}$ by the following equation that describes the near-tip COD profile for a straight crack (Irwin, 1958; Lawn, 1993), 
Tab. 1: The values of crack tip toughness $\left(K_{I O, I r}\right.$ and $\left.K_{I I I O, I r}\right)$ based on Irwin's 'near-field' solutions [Irwin, 1958; Lawn, 1993], and the crack closure stress near the crack tip, the width and length of the cohesive zone and the corresponding crack tip toughness based on cohesive zone solutions developed for Dugdale-Muskhelishvili crack model by Goodier and Field [Dugdale, 1960; Goodier and Field, 1963; Hahn and Rosenfeld, 1965; Hahn, 1976].

\begin{tabular}{|c|c|c|c|c|c|c|}
\hline \multirow[b]{2}{*}{ Crack } & \multicolumn{2}{|c|}{ Irwin's Solution } & \multicolumn{4}{|c|}{ DM Crack Model's Solution } \\
\hline & $\begin{array}{c}K_{I 0, I r} \\
\left(\mathrm{MPa}^{0.5}\right)\end{array}$ & $\begin{array}{c}K_{I I I 0, I r} \\
\left(\mathrm{MPa}^{0.5}\right)\end{array}$ & $\bar{\sigma}_{b r}(\mathrm{MPa})$ & $\lambda(\mu \mathrm{m})$ & $\delta / 2(\mathrm{~nm})$ & $\begin{array}{c}K_{I 0, c z} \\
\left(\mathrm{MPa}^{0.5}\right)\end{array}$ \\
\hline 'along'-1 & 0.64 & 0.019 & 168 & 10.06 & 22 & 0.84 \\
\hline 'along'-2 & 0.94 & 0.027 & 754 & 1.61 & 16 & 1.51 \\
\hline 'across'-1 & 0.52 & 0.048 & 240 & 6.55 & 20 & 0.95 \\
\hline 'across'-2 & 0.54 & 0.141 & 434 & 3.18 & 18 & 1.22 \\
\hline 'across'-3 & 1.14 & 0.052 & 779 & 1.26 & 13 & 1.38 \\
\hline 'across'-4 & 1.62 & 0.076 & 580 & 1.56 & 12 & 1.15 \\
\hline
\end{tabular}
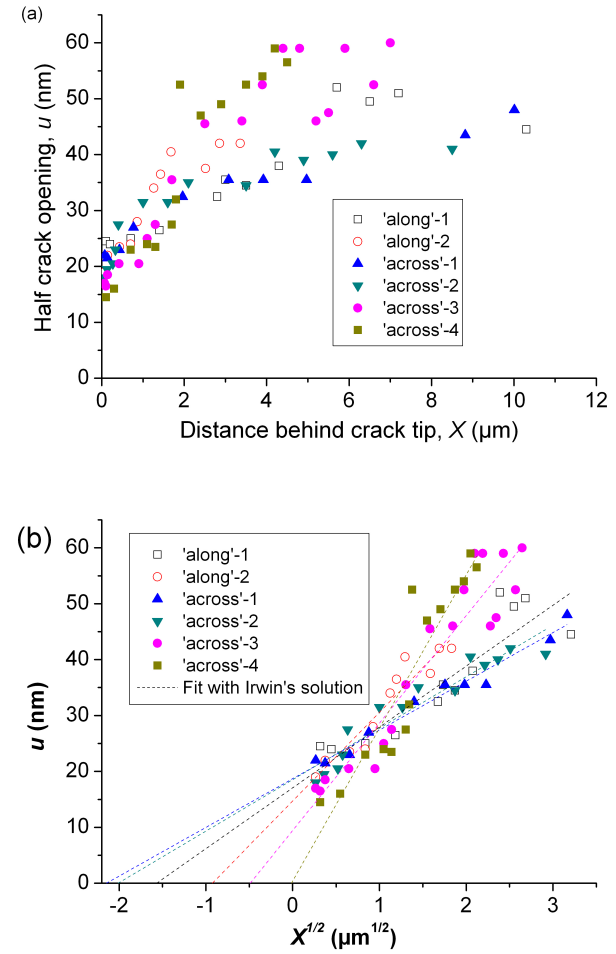

Fig. 2: The calculation of $K_{I O, I r}$. (a) $u$ versus $X$ profile for all cracks. The crack opening $2 u$ is around $40 \mathrm{~nm}$ and does not lie within the measurement uncertaintay of $<20 \mathrm{~nm}$. (b) $u$ versus $X^{I / 2}$. The slopes are used to calculate $K_{I O, I r}$ with Eq. (1).

$$
u=\frac{K_{I 0, I r}}{E} \cdot \sqrt{\frac{8 \cdot X}{\pi}} \cdot\left(1-v^{2}\right)
$$

$u$ is the half COD between two opposing crack walls $(u=\mathrm{COD} / 2), X$ is the distance from the crack tip, $E$ and $v$ are the elastic modulus and Poisson's ratio of enamel and are taken as $E=87 \mathrm{GPa}$ (Xu et al., 1998) and $v=0.23$ (Waters, 1980). (The lower case annotation 'Ir' indicates that the values are calculated based on Irwin's parabolic 'near-field' solution). The value of $E=87 \mathrm{GPa}$ is the average elastic modulus values derived from both the longitudinal and transverse orientations of enamel from Vickers indentation under comparable load as in our study ( $\mathrm{Xu}$ et al., 1998). The crack opening up to $10 \mu \mathrm{m}$ behind the crack tip are not associated with observable ligament bridges and are used in the calculation. A key assumption in utilizing the Irwin's 'near-field' solutions is that the crack walls behind the tip remain free of traction (Irwin, 1958; Lawn, 1993). $u$ versus $X^{1 / 2}$ was plotted (Fig. 2(b)); the slopes are used to calculate $K_{I 0, I r}$ based on Eq. (1) but without forcing the intercept-y to zero. A total of 6 crack tip toughness measurements are reported here: 2 'along' cracks and 4 'across' cracks. Both of them show similar values with $K_{I O, I r, \|}=0.63-0.91 \mathrm{MPa} \cdot \mathrm{m}^{0.5}$ and $K_{I O, I r, \perp}=0.50$ 1.58MPa.m ${ }^{0.5}$ (Tab. 1).

Similar to Eq. (1), the mode III crack tip toughness, $K_{I I I, \text { Ir }}$ can be described by the following equation (Irwin, 1958; Lawn, 1993), with $u_{z}$ being the height difference of two crack walls (Fig. 1(e)),

$$
u_{Z}=\frac{K_{I I I 0, I r}}{E} \cdot \sqrt{\frac{8 \cdot X}{\pi}} \cdot(1+v)
$$

Similarly, $u_{z}$ versus $X^{1 / 2}$ were plotted to calculate $\quad K_{I I I, I r, \|}=0.02-0.03 \mathrm{MPa} . \mathrm{m}^{0.5}$ and

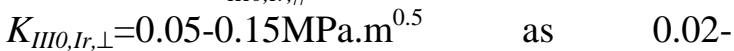
$0.15 \mathrm{MPa} . \mathrm{m}^{0.5}$. The results are summarized in

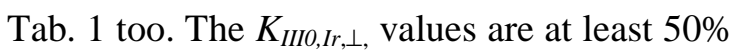
higher than $K_{I I I, I r, \|}$. However, these values are an order of magnitude smaller than the values of $K_{I O, I r}$, and could be deemed negligible.

(C) Cohesive zone: The $u$ versus $X$ plot (Fig. 2(a)) seemingly shows a constant 
a

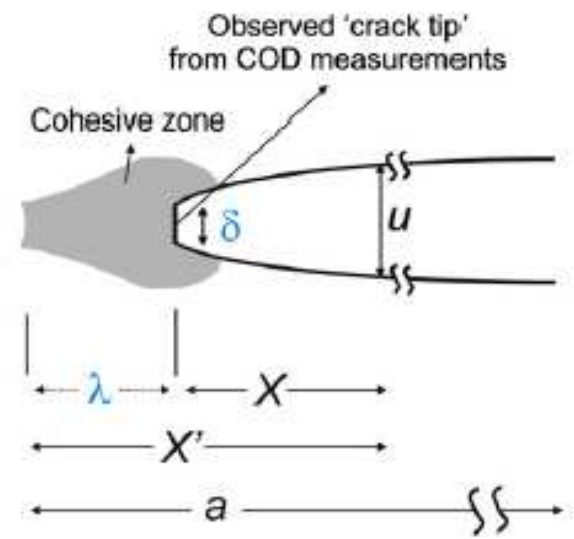

C

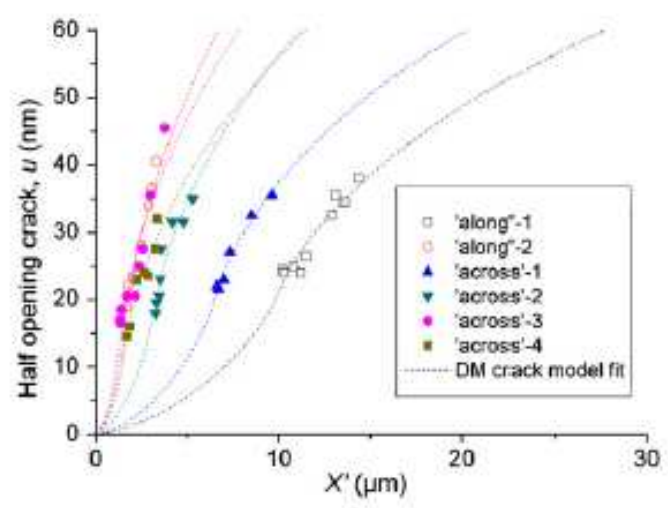

b
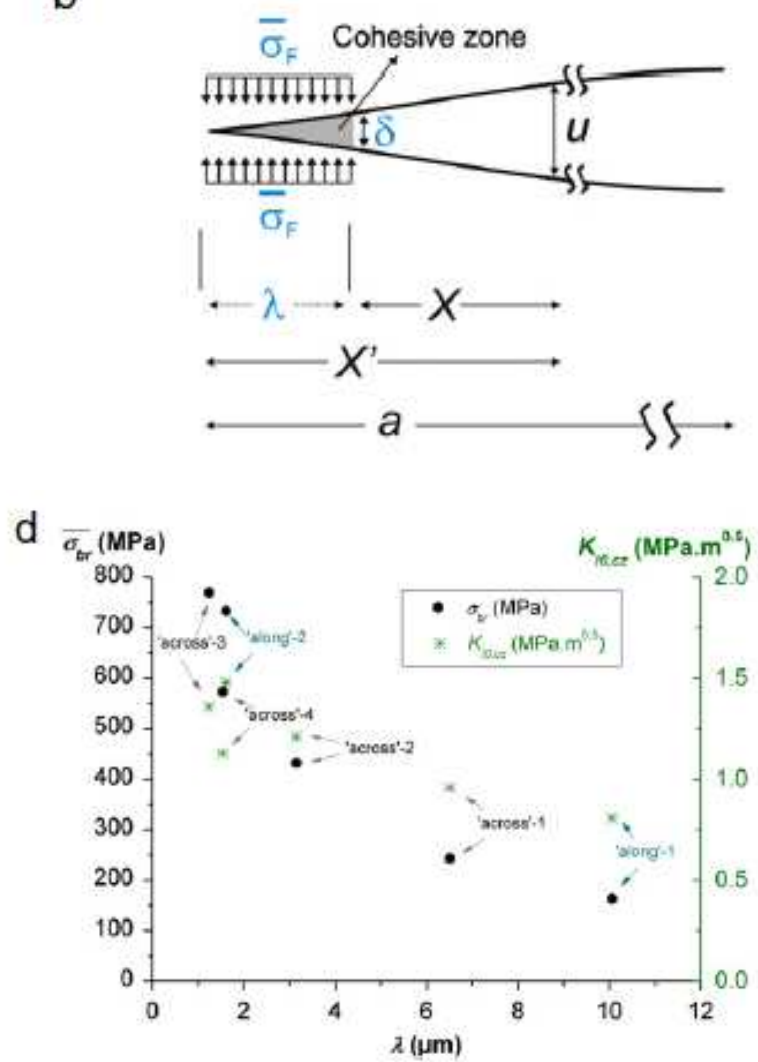

Fig. 3: Model of a Dugdale-Muskhelishvili (DM) crack and the cohesive zone parameters fitting. (a) The actual crack and the cohesive zone ahead of the crack tip. (b) the DM model. (c) $u$ versus $X$ ' profile for the original data points used for fitting with DM's cohesive zone solutions together with their fitted curves (dashed lines) $\left(X^{\prime}=X+\right.$

$\lambda$ ). (d) $\bar{\sigma}_{b r}$ and $K_{I O, c z}$ versus $\lambda$.

$u \approx 20 \mathrm{~nm}$ half opening at the beginning of the measured COD (at $X=0$ ). This crack opening $(2 u)$ is around $40 \mathrm{~nm}$ and does not lie within the measurement uncertainties of $\leq 10 \mathrm{~nm}$. We interpret this finite crack tip opening, $\delta$ as the end of a cohesive zone length $\lambda$ with constant bridging stresses, $\bar{\sigma}_{b r}$ (Fig. 3(a) and (b)). The load-displacement solution developed by Goodier and Field for Dugdale- Muskhelishvili crack model (Fig. 3(b)) (Goodier and Field, 1963; Hahn, 1976; Hahn and Rosenfeld, 1965) is used to calculate $\bar{\sigma}_{b r}$ and $\lambda$,

$u=\frac{a \cdot \bar{\sigma}_{b r}}{\pi \cdot E^{\prime}}\left(\cos \varphi \cdot \ln \frac{\sin ^{2}(\vartheta-\varphi)}{\sin ^{2}(\vartheta+\varphi)}+\cos \vartheta \cdot \ln \frac{(\sin \vartheta+\sin \varphi)^{2}}{(\sin \vartheta-\sin \varphi)^{2}}\right)$

where

$\varphi=\arccos \left(\frac{a-X-\lambda}{a}\right) \quad, \quad \vartheta=\arccos \left(\frac{a-\lambda}{a}\right) \quad$ and $E^{\prime}=E /\left(1-v^{2}\right)$.

$a$ is crack length and is taken as $a_{\|}=100 \mu \mathrm{m}$ for along cracks and $a_{\perp}=50 \mu \mathrm{m}$ for across cracks.
(When the values of $a$ differ by $\pm 20 \mu \mathrm{m}$ from the above values, the results of $\bar{\sigma}_{b r}, \lambda, \delta / 2$ and $K_{I 0, c z}$ in Tab. 1 differ by $<5 \%$ ). Since the half CODs at $X=0$ in Fig. 2(a) are interpreted as the finite crack tip opening of the cohesive zones $\delta, \lambda$ has been added as the $\mathrm{X}$-offset in $\varphi$ in Eq. (3) to locate the tip of the cohesive zone. The onset of the crack is shifted leftward and relabeled with $X^{\prime}$ where $X^{\prime}=X+\lambda$ (Fig. 3(a) and (b)). Since the model is only valid for the region near the crack tip, only data points up to $4.3 \mu \mathrm{m}$ behind the crack tip (the length scale of one enamel rod) is used for the fitting procedures. MATLAB's curve fitting toolbox with custom equations was used for the curve fitting. The solution depends on the start values of the iteration. The fitting program iterates for the same values of $\bar{\sigma}_{b r}$ and $\lambda$ within the range of input values of $\bar{\sigma}_{b r} \in[1-2000 M P a]$ and $\lambda \in[0.1-50 \mu \mathrm{m}]$, resulted in $\bar{\sigma}_{b r(\|)}=163-734 M P a, \bar{\sigma}_{b r(\perp)}=243-770 M P a$ 

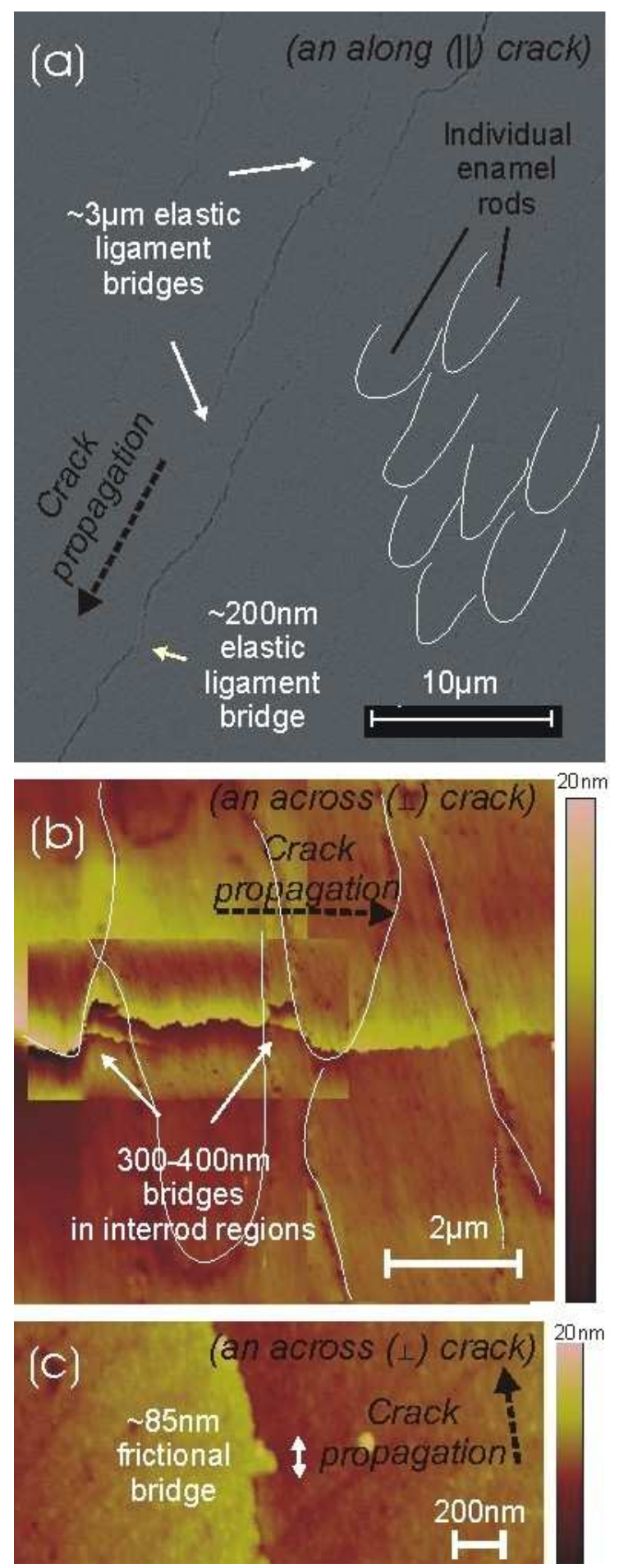

Fig. 4: Crack bridges in enamel. (a) $\sim 3 \mu \mathrm{m}$ intact ligament bridges, (a) and (b) 200-400nm bridges, (c) a nano-sized $\sim 85 \mathrm{~nm}$ frictional bridge corresponding to the length scale of one enamel rod, several enamel crystallites and approximately one crystallite respectively.

and $\lambda_{b r(\|)}=1.6-10.1 \mu m, \lambda_{b r(\perp)}=1.2-6.5 \mu m$

(Tab. 1). $\delta / 2$ is calculated from Eq. 3 by inserting $X=0$ and the corresponding $\bar{\sigma}_{b r}$ values as $\delta / 2=12-22 \mathrm{~nm}$ (Tab. 1$)$. So, $\delta_{(\|)}=16-22 \mathrm{~nm}, \delta_{(\perp)}=12-21 \mathrm{~nm}$. The
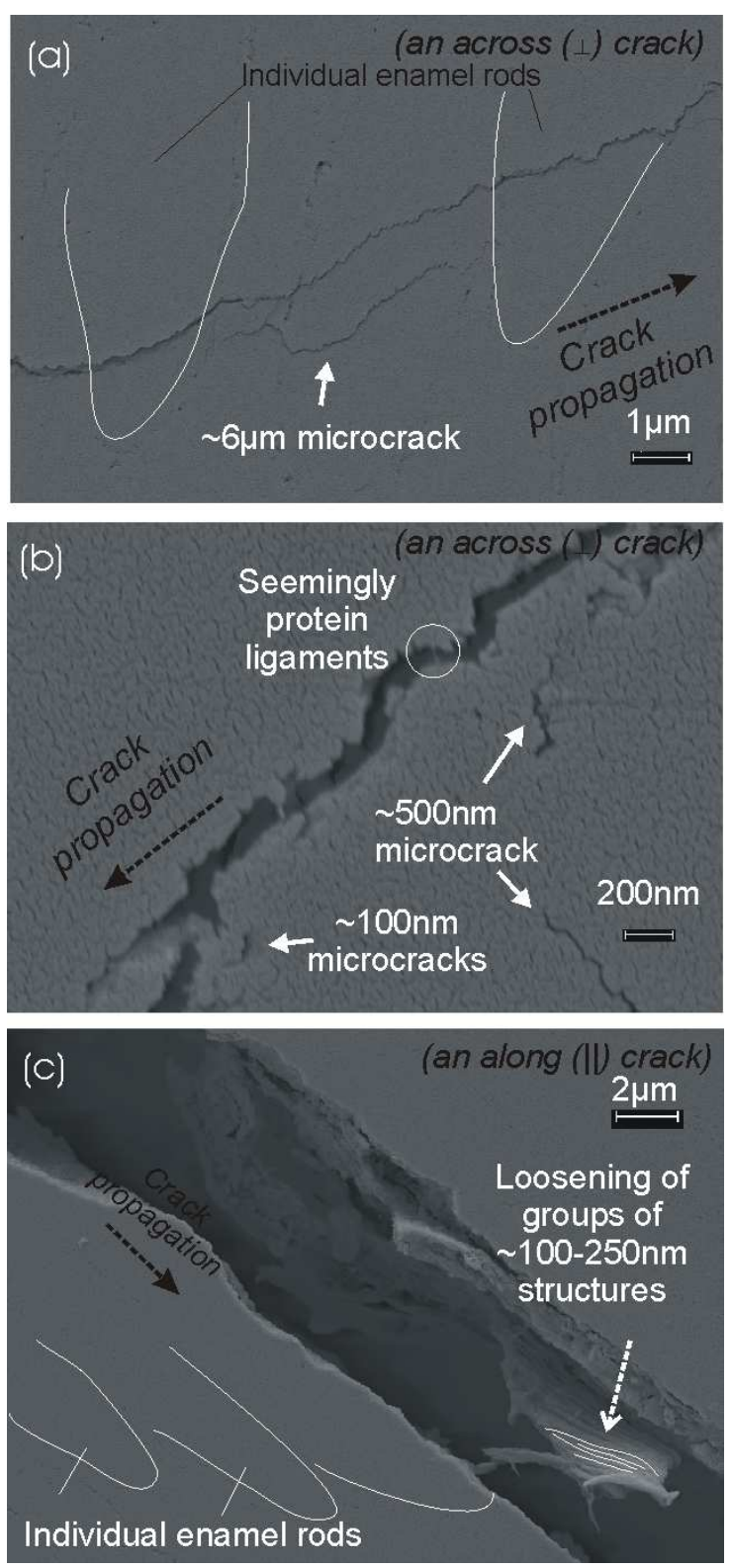

Fig. 5: Microcracks and seemingly protein ligaments. (a) A microcrack across a few enamel rods $(\sim 6 \mu \mathrm{m})$ and (b) within an enamel rod at the interface of HAP crystallites (100-500nm). The ligament inside the crack, circled in white in (b) is seemingly protein ligaments. (c) Loosening of groups of crystallites $(\sim 100-250 \mathrm{~nm})$ indicates the presence of microcracks.

data points together with the fitted curves based on Eq. 3 are plotted as $u$ versus $X^{\prime}$ (Fig. $3(\mathrm{c})$ ).

The criterion for crack propagation under monotonic loading, $K_{I 0}=\sqrt{\left(E /\left(1-v^{2}\right)\right) \cdot J_{c}}$ with $J_{c}=2 \int_{0}^{u} \sigma(u) d u$ for the near-tip zone (Cox and Marshall, 1994) can be used to calculate crack-tip toughness based on the calculated $\bar{\sigma}_{b r}$ and $\delta$ values. Since the bridging stress, 
$\bar{\sigma}_{b r}$ in the applied cohesive model is constant,

$J_{c}=2 \cdot \bar{\sigma}_{b r} \cdot u=\bar{\sigma}_{b r} \cdot \delta$. Therefore, the crack tip toughness is calculated according to the equation,

$$
K_{I 0, c z}=\sqrt{\left(E /\left(1-v^{2}\right)\right) \cdot \bar{\sigma}_{b r} \cdot \delta}
$$

as $K_{I 0, c z}=0.8-1.5 \mathrm{MPa} \cdot \mathrm{m}^{0.5}$ (Tab. 1). (The lower case annotation ' $c z$ ' indicates that the values are calculated based on the cohesive zone solutions.) $\bar{\sigma}_{b r}$ and $K_{I 0, c z}$ are plotted versus $\lambda$ for better visualization (Fig. 3 (d)).

(C) Toughening mechanisms: Crack bridging and microcracks of different lengths scales are identified. Crack bridges on the length scale of one enamel $\operatorname{rod}(\sim 3 \mu \mathrm{m})$, bundles of crystallites $(300-400 \mathrm{~nm})$ and approximately one crystallite $(\sim 85 \mathrm{~nm})$ were observed (Fig. 4). Similar to the bridges at multiple length scales, microcracks of $\sim 6 \mu \mathrm{m}$ and 100-500nm were detected (Fig. 5(a) and (b)). Additionally, loosenings of groups of crystallites (Fig. 5(c)) are also observed. Fig. 5(b) also shows possible indication of proteins. The cracks paths show undulatory pattern.

\section{Discussion}

Enamel's crack tip toughness was reported as $K_{I 0}=0.5-0.8 \mathrm{MPa} \cdot \mathrm{m}^{0.5}$ in a previous study which based on enamel CT specimens (Bajaj and Arola, 2009a). These lies at the lower range of our measured $K_{I 0}=0.6-1.6 \mathrm{MPa} \cdot \mathrm{m}^{0.5}$. The wide variations of our reported $K_{I 0}$ are hypothesized to be caused by different morphological surroundings around a crack tip and will be discussed in the last paragraph of discussion.

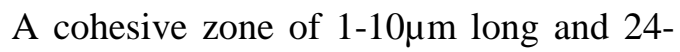
$44 \mathrm{~nm}$ wide with an average bridging stress of $163-770 \mathrm{MPa}$ is calculated to occur at the crack tip. Within the cohesive zone wedge-shaped inelastic processes prevail which are decoupled from the linear-elastic field outside the zone (Hahn and Rosenfeld, 1965). Possible inelastic processes within the zone are the separation of the so-called 'sacrificial bonds' (Fantner et al. 2005), protein bridging, protein breakage, microcracks, minerals ligament bridging and/or mineral fracture. An up to $10 \mu \mathrm{m}$ long zone means that multiple crystallite nanofibers or even multiple enamel rods are included in the inelastic process and the bridging stress is not only caused by protein bridging alone. Experimental studies showed that the ultimate stress of proteins such as ligaments (mainly collagen), tendon (mainly collagen) and horn (mainly keratin) are $2.5-7 \mathrm{MPa}, 70 \mathrm{MPa}$ and 260MPa respectively (Sikoryn and Hukins, 1990; Bigliana et al., 1992, Meyers et al., 2008; Druhala and Feughelman, 1974) and are generally lower than the calculated 163$770 \mathrm{MPa}$ Secondly, the stress intensity shielding contributed by the protein bridging can be estimated by using a Dugdale-zone model, $K_{p}=2 * \sigma_{p} * f_{p} *\left(2 * l_{p} / \pi\right)^{0.5}$ with $K_{p}$ the stress intensity due to protein bridging, $\sigma_{p}=2.5$ $260 \mathrm{MPa}$ the yield strength of protein, $f_{p}=0.1$ the area fraction of protein bridging ligaments (estimated based on the volume fraction of protein in enamel), $l_{p}=1-10 \mu \mathrm{m}$ the protein bridging zone length (Evans and McMeeking, 1986). $K_{p}$ is calculated as $0-0.13 \mathrm{MPa} \cdot \mathrm{m}^{0.5}$ and is much smaller than the crack tip toughness. Mineral fracture is unlikely to occur in the cohesive zone according to the following calculation. The theoretical strength of hydroxyapatite crystallites can be estimated by $\sigma_{m}=E_{m} / 30=4.3 \mathrm{GPa} \quad\left(E_{m}=129 \mathrm{GPa}\right.$ (Ang et. al, 2009)). Assuming that a material's failure is due to the fracture of mineral phase, the strength of different hierarchical level can be calculated based on the formula $\sigma_{n+1}=\varphi_{n} * \sigma_{n}$ $12, \sigma_{n}$ and $\sigma_{n+} 1$ the strength of the hierarchical structure $n$ and $n+1, \varphi_{n}$ the volume fraction of minerals at hierarchical structure $n$ (Gao, 2006). $\varphi_{n}$ is assumed to be constant for all hierarchical level and is taken is $0.9, \varphi=0.9$. Since a single crystallite fiber is level 0 (Gao, 2006), the strength of first hierarchical structure level, multiple crystallites, can be estimated by using the formula $\sigma_{l}=\varphi^{*} \sigma_{0}$ $/ 2=\varphi^{*} \sigma_{m} / 2=1.9 G P a$. Similarly, the strength needed for minerals failure of the second hierarchical structure level, multiple enamel rods is $\sigma_{2}=\varphi^{*} \sigma_{l} / 2=0.9 \mathrm{GPa}$. Hence, the strength of the first hierarchical level is significantly higher than the calculated cohesive zone stresses, whereas the second hierarchical level has a strength close to the upper limit of the cohesive zone stresses.

Interrod regions are relatively rich in organic phase compared to intrarod regions and are less resistant against fracture. Previous studies of enamel fracture have observed cracks more commonly along rod boundaries than running through rods (Ramussen et al. 1976). Bridges of $10-20 \mu \mathrm{m}$ wide in enamel have been observed in several previous experimental studies (Bajaj and Arola, 2009a, 

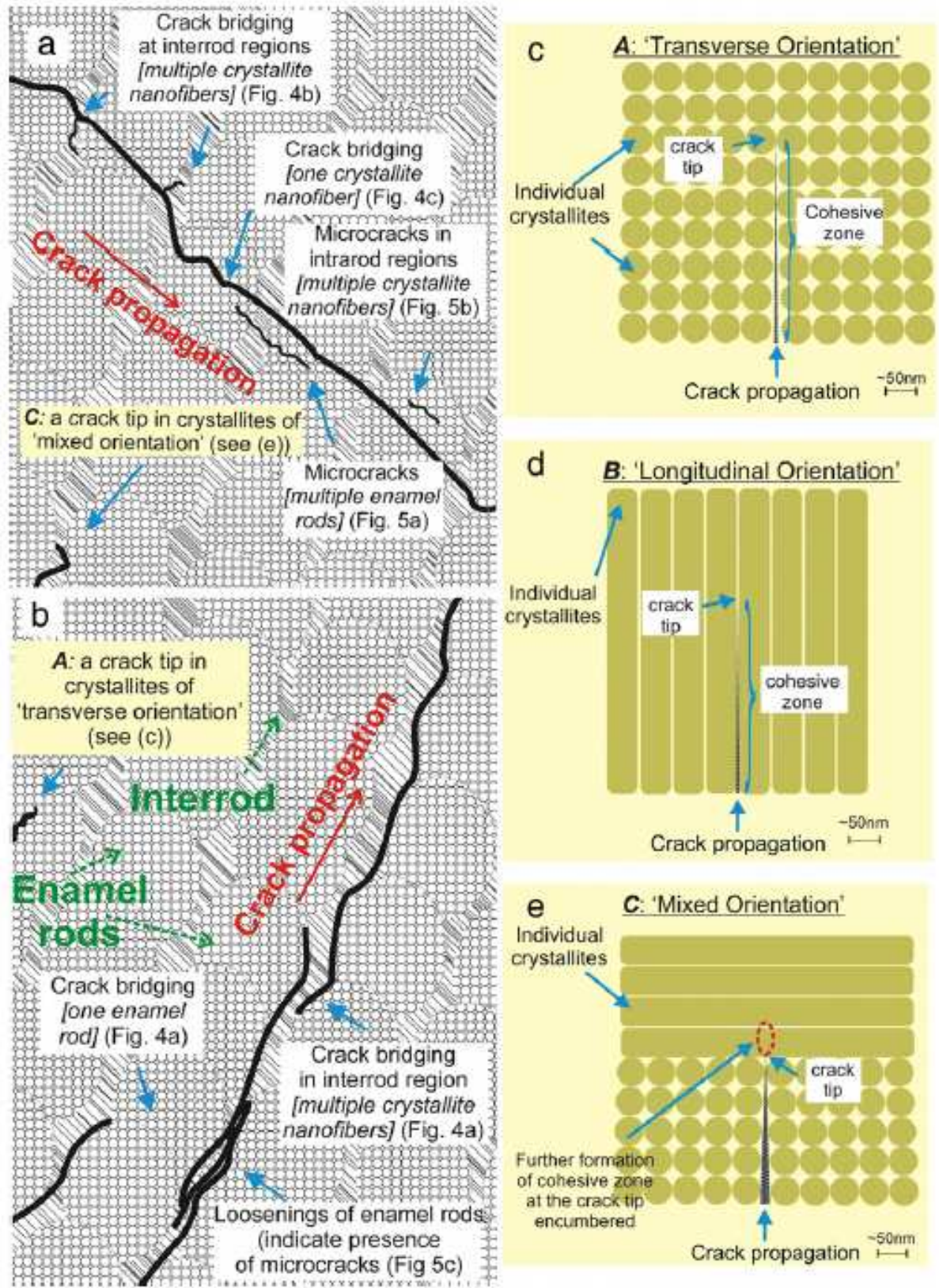

Fig. 6: Toughening mechanisms in enamel of zero level (single crystallite nanofiber), first level (multiple crystallite nanofibers but within one enamel rod or interrod region) and second level (multiple enamel rods) hierarchical structures. (a) showed an ' $\perp$ ' crack together with the observed crack bridging at interrod regions (first level; multiple crystallites), crack bridging within one enamel rod (zero level; one enamel crystallite); microcracks that span across two enamel rods (second level) and microcracks in intrarod region (first level, multiple enamel crystallites). (b) showed an 'along' crack together with the observed crack bridging that involve one enamel rod (first level), crack bridging in interrod region (first level, multiple crystallites), as well as loosenings of prism structures that indicated the presence of microcracks. (c) to (e) are hypothesis of 3 possible morphological surroundings of crack tip and the cohesive zone in (A) 'transverse orientation' (B) 'longitudinal orientation' and (C) 'mixed orientation'. (Possible locations where configuration (A) and (C) happened are indicated in the two crack tips in (a) and (b) illustration. Configuration (B) could happen, for example, when a crack propagates along the axis of an enamel rod.

2009b; Bechtle et al., 2010a; Bajaj et al., 2008); they span across multiple rods. In this study, bridges of $3 \mu \mathrm{m}$ wide are observed along interrod regions of the width of one enamel rod (Fig. 4(a)). The $200 \mathrm{~nm}$ ligament bridges are observed to happen at an interrod region and encompass groups of crystallite fibers (Fig, 4(a)). Even a single crystallite in the intrarod region is capable to form nanoscale sized $\sim 85 \mathrm{~nm}$ bridges (Fig. 4(c)).

Besides providing weak interface to form bridges, interrod regions also reinforce 
enamel's structure by hindering crack propagation when a crack runs across them but not along them (Fig. 4(b)). The intrarodinterrod boundaries are locations where an abrupt change in crystallite orientation occurs (Bajaj and Arola, 2009a; Bechtle et al., 2010b; Glimcher et al., 1965), therefore a crack needs higher energy to propagate through them.

Summarized, the presence of organic phase as well as abrupt change in crystallite orientations in interrod region coupled with enamel's hierarchical structure are obviously advantageous for bridge formation at different length scales - several enamel rods $(10-20 \mu \mathrm{m})$, one enamel rod $(\sim 3 \mu \mathrm{m})$, groups of crystallites around interrod regions (200-400nm) and even one crystallite $(\sim 85 \mathrm{~nm})$. Such ability of a material to form bridges from $\sim 20 \mu \mathrm{m}$ down to $\sim 85 \mathrm{~nm}$ has neither been observed before in enamel nor in commercial ceramic materials.

Small droplets adjacent to the the crack in enamel are observed and are believed to be resulted by the loosenings of interprismatic spaces due to microcracks; they occur along interrod regions (Bajaj and Arola, 2009b). In our study, we observed microcracks of the length scales of several enamel rods $(\sim 6 \mu \mathrm{m})$ (Fig. 5(a)) and multiple crystallites (100$500 \mathrm{~nm}$ and occurred in an intrarod region) (Fig. 5(b)). One may argue that the observed microcracks under SEM (Fig. 5(a) and (b)) are artifact crackings due to the SEM sample preparation procedures (for example, dehydration effect in a vacuum chamber). However, such were also observed under AFM investigation in ambient conditions. Loosening of crystallites structure (Fig. 5(c)) along the crack path is also a trace of the presence of microcracks.

The wide range of calculated $K_{I 0}$ values is hypothesized to be caused by different morphological surroundings at the crack tip. The cohesive zone could occur in at least 3 surroundings in interrod/intrarod region: 'transverse orientation', 'longitudinal orientation' and 'mixed orientation' as illustrated in Fig. 6. Note that both 'transverse' or 'longitudinal' orientations could happen for both modes 'along' (mainly at interrod regions) and 'across' (mainly at intrarod regions) crack propagation. The cohesive zone is expected to be different in three situations. In the case of 'transverse orientation' and 'longitudinal orientation', a cohesive zone is formed relatively easy in comparison to a 'mixed-mode orientation', where the crack tip reaches a boundary with an abrupt change in crystallite orientations. The $K_{I 0}$ measured from both 'transverse orientation' and 'longitudinal orientation' is expected to be low in comparison to 'mixed orientation'. For a longer cohesive zone (up to $10 \mu \mathrm{m}$ ), the situation in the cohesive zone would be a combination of the mentioned surroundings above. The limitation of this study is that the crack tip toughness could not be correlated to the crystallite orientation and in-situ crack propagation could not be observed. A potential method for such observation is utilizing etching procedures to reveal the crystallite orientations after the COD measurements.

\section{Conclusions}

Irwin's 'near-field' solution is used to calculate the mode I crack tip toughness of enamel, $K_{I O, I r}$ as $0.5-1.6 \mathrm{MPa} \cdot \mathrm{m}^{0.5}$. The mode III crack tip toughness $\left(0.02-0.15 \mathrm{MPa} . \mathrm{m}^{0.5}\right)$ is comparatively negligible. Besides, the cohesive zone model of a DugdaleMuskhelishvili crack is used to calculate the closure stress near the crack tip, $\bar{\sigma}_{b r}$ as 163 $770 \mathrm{MPa}$, with a cohesive zone size of 1.6$10.1 \mu \mathrm{m}$ long and $24-44 \mathrm{~nm}$ wide, which might be attributed to the microcracks, the bridging of protein and hydroxyapatite ligaments. These parameters of the cohesive zone are used to calculate $K_{I 0, c z}=0.8-1.5 \mathrm{MPa} \cdot \mathrm{m}^{0.5}$. Interrod regions reinforce enamel by bridge formation along interrod regions but also hindered crack propagation by significant change in crystallite orientation compared to those in intrarod region. Crack bridges and microcracks were identified to occur across different length scales: the bridges are from $\sim 85 \mathrm{~nm}$ to $\sim 3 \mu \mathrm{m}$ and the microcracks are from $100-500 \mathrm{~nm}$ to $\sim 6 \mu \mathrm{m}$ respectively in this study.

\section{Acknowledgement}

The authors wish to express gratitude to German Research Foundation for financial support. Special thanks are extended to Dr. Hans Jelitto, Dipl.-Ing. Hüseyin Özcoban, Dipl.-Ing. Sabine Bechtle and Dipl.-Ing. Andrea Engert from Hamburg University of Technology for valuable scientific discussions and Dipl.-Ing. Anja Borchert for her kind technical assitance. 


\section{References}

Ang, S. F. Bortel, E. L., Swain, M. V., Klocke, A., Schneider, G. A., 2009. Size-dependent elastic/inelastic behavior of enamel over millimeter and nanometer length scales. Biomaterials 31(7), 1955-1963.

Bajaj, D., Nazari, A., Eidelman, N., Arola, D.D., 2008. A comparison of fatigue crack growth in human enamel and hydroxyapatite. Biomaterials 29(36), 4847-4854.

Bajaj, D., Arola, D.D., 2009a. On the R-curve behavior of human tooth enamel. Biomaterials 30, 4037-4046.

Bajaj, D., Arola, D., 2009b. Role of prism decussation on fatigue crack growth and fracture of human enamel. Acta Biomater. 5(8), 30453056.

Bechtle, S., Habelitz, S., Klocke, A., Fett, T., Schneider, G.A., 2010a. The fracture behaviour of dental enamel. Biomaterials 31(2), 375-384.

Bechtle, S., Fett, T.; Rizzi, G.; Habelitz, S.; Schneider, G. A., 2010b. Mixed-mode stress intensity factors for kink cracks with finite kink length loaded in tension and bending: Application to dentin and enamel. Journal of the Mechanical Behavior of Biomedical Materials, 3, 303-312.

Bigliana L. U., Pollock R. G., Soslowsky L. J., Flatow E. L., Pawluk R. J., Mow V. C., 1992. Tensile properties of the inferior glenohumeral ligament, J. Orthop. Res. 10(2), 187-197.

Bodecker, C.F, 1953. Enamel lamellae and their origin. J. Dent. Res. 32, 239-245.

Chai, H., Lee, J.J.W., Conatantino, P.J., Lucas, P.W., Lawn, B.R., 2009. Remarkable resilience of teeth. PNAS Early Edition 106(18), 1-5.

Cox, B.N., Marshall, D.B., 1994. Concepts for bridged cracks in fracture and fatigue. Acta Metall. Mater. 42(2), 341-363.

Druhala M., Feughelman M., 1974. Dynamic mechanical loss in keratin at low temperatures, Colloid Polym. Sci. 252, 381-391.

Dugdale, D. S., 1960. Yielding of steel sheets containing slits. J. Mech. Phys. Solids 8(2), 100104.

Fantner, G.E., Hassenkamp, T., Kindt, J.H., Weaver, J.C., Birkedal, H., Pecheniki, L., Cutroni, J.A., Cidade, G.G., Stucky, G.D., Morse, D.E., Hansma, P.K., 2005. Sacrificial bonds and hidden length dissipate energy asmineralized fibrils separateduring bone fracture. Nat. Mater. 4, 612-616.

Fett, T., Fünfschilling, S., Hoffman, M. J., Oberacker R., Jelitto, H., Schneider, G. A., 2008. $\mathrm{R}$-curve determination for the initial stage of crack extension in $\mathrm{Si}_{3} \mathrm{~N} 4$. J. Am. Ceram. Soc. 91(11), 3638-3642.

Frazier, P.D., 1968. Adult human enamel: an electron microscopic study of crystallite size and morphology. J. Ultrastruct. Res. 22, 1-11.
Fünfschilling, S., Fett, T., Hoffmann, M.J., Oberacker, R., Jelitto, H., Schneider, G.A., Härtelt, M., Riesch-Oppermann, H., 2009. Bridging stresses of R-curves of silicon nitrides. J. Mater. Sci. 44(14) 3900-3904.

Gao, 2006. Application of fracture mechanics concepts to hierarchical biomechanics of bone and bone-like materails. Int. J. Fracture 138, 101137.

Glimcher, M.L., Daniel, E.J., Travis, D.F., Kamhi, S., 1965. Electron optical and X-ray diffraction studies of the organization of the inorganic crystals in embryonic bovine enamel. $\mathbf{J}$ Ultrastruct. Res. 50(Supp 7), 1-77.

Goodier, J. N., Field, F. A., 1963. Fracture of Solids. Edited by Drucker and Gilman, Interscience, New York, pp. 103.

Gray, H., Bannister, L.H., Berry, M.M., Williams, P.L., 1995. Gray's anatomy: The anatomical basis of medicine \& surgery, thirty-eighth ed. Churchill Livingstone, New York, pp. 1710.

Hahn, G.T., Rosenfeld, A.R., 1965. Local yielding and extension of a crack under plane stress. Acta Metall., 13, 293-306.

Hahn, H.G., 1976. Bruchmechanik: Einführung in die theoretischen Grundlagen. Teubner, Stuttgart, pp. 67-72.

Hayashi, Y., 1994. High resolution electron microscopy of a small crack at the superficial layer of enamel. J. Electron. Microsc. 43, 398401.

Healy, K.E., 1998. Dentin and Enamel, in: Black, J., Hastings, G. (Eds.), Handbook of biomaterials properties. Springer-Verlag, pp. 25.

Irwin, G. R. 1958. Fracture, in: Handbuch der Physik Vol. 6. Springer-Verlag, Berlin, pp. 551.

Kounga Nijwa, B., Fett, T, Lupascu, D. C., Rödel, J., 2003. Crack-tip toughness of a soft lead zirconate titanate. J. Am. Ceram. Soc. 86(11), 1973-1975.

Lawn, B., 1993. Fracture of brittle solids, second ed. Cambridge University Press, Cambridge, pp. 24-26.

Maas, M.C., Dumont, E.R., 1999. Built to last: the structure, function and evolution of primate dental enamel. Evol. Anthrop. 8, 133-152.

Meschke, F., Alves-Ricardo, P., Schneider, G.A., Claussen, N., 1997. Failure behavior of alumina and alumina/silicon carbide nanocomposites with natural and artificial flaws. J. Mater. Res. 12(129), 3307-3315.

Meschke, F., Raddatz, O., Kolleck, A., Schneider, G. A., 2000. R-curve behavior and crack-closure stressed in barium titanate and (Mg,Y)-PSZ cramics, J. Am. Ceram. Soc., 83, 353-361.

Meyers M. A., Chen P. Y., Lin A. Y. M., Seki Y., 2008. Biological materials: structure and mechanical properties, Prog. Mater. Sci. 53(1), 1-206 (Pg 29).

Muskhelishvili, N. I., 1953. Some problems of the mathematical theory of elasticity, Noordhoff, Gronigen, pp. 340. 
Nishimura, Y., Tsubota, Y., Fukushima, S., 2008. Influence of cyclic loading on fiber post and composite resin core. Dent. Mater. J. 27, 356361.

Oesterle, L.J., Shellhart, W.C., Belanger, G.K., 1998. The use of bovine enamel in bonding studies. Am. J. Ortho. 114, 514-520.

Özcoban, H., Jelitto, H., Schneider, G. A., 2010. Influence of finite notch root radius and optically determined crack length on the measured fracture toughness of brittle materials. J. Eur. Ceram. Soc. 30(7), 1579-1583.

Ramussen, S.T., Patchin, R.E., Scott, D.B., Heuer, A.H., 1976. Fracture properties of human enamel and dentin. J. Dent. Res. 55, 154-164.

Rödel, J., Kelly, J. F., Lawn, B. R., 1990. In situ measurements of bridged crack interfaces in the scanning electron microscope. J. Am. Ceram. Soc. 73(11), 3313-3318.

Roedel, J., 1992. Crack closure forces in ceramics: characterization and formation. J. Eur. Ceram. Soc. 9, 323-334.

Ruse, N.D., Smith, C.C., Torneck, C.D., Titley, K.C., 1990. Preliminary surface analysis of etched, bleached, and normal bovine enamel. J. Dent. Res. 69, 1610-1613.

Sanches, R.P., Otani, C., Damiao, A.J., Miyakawa, W., 2009. AFM characterization of bovine enamel and dentine after acid etching. Micron 40, 502-506.

Sikoryn T. A., Hukins D. W. L., 1990. Mechanism of failure of the ligamentum flavum of the spine during in vitro tensile tests. J Orthop Res 8(4), 586-591.

Ten Cate, A. R., 2003. Oral histology development, structure and function, $7^{\text {th }}$ edition, Mosby, St Louis.

Waters, N.E., 1980. Some mechanical and physical properties of teeth, in: Vincent, J.F.V., Currey, J.D. (Eds), The Mechanical Properties of Biological Materials. Cambridge University Press, Cambridge, pp. 99-136.

Xu, H.H.K., Smith, D.T., Jahanmir, S., Romberg, E., Kelly, J.R., Thompson, V.P., Rekow, E.D., 1998. Indentation damage and mechanical properties of human enamel and dentin. J Dent. Res. 77(3), 472-480. 